\title{
Self-Reported Incident Type 2 Diabetes in the Ibadan Study of Ageing: Relationship with Urban Residence and Socioeconomic Status
}

\author{
Williams O. Balogun Oye Gureje \\ College of Medicine, University of Ibadan and University College Hospital, Ibadan, Nigeria
}

\author{
Key Words \\ Incident diabetes · Urban residence $\cdot$ Socioeconomic \\ status $\cdot$ Ageing
}

\begin{abstract}
Background: There is no incident study of diabetes among elderly Nigerians and it is unclear what factors may constitute risks for the condition in this society undergoing rapid social changes. Objective: This study explores the link between urban residence and socioeconomic status, and incident diabetes among community-dwelling elderly Nigerians. Methods: A cohort of 2,149 persons, aged 65 years and above, were recruited through a clustered multistage sampling in eight contiguous predominantly Yoruba-speaking states in south-western and north-central regions of Nigeria. Follow-up evaluation was conducted approximately 39 months after the baseline assessments. Face-to-face assessments obtained self-report of chronic medical conditions, including diabetes, using a standardized checklist as well as information on social factors, including residence. Incident diabetes was determined among persons who were free of the problem at baseline $(n=1,330)$. Results: At follow-up, 38 subjects had developed diabetes giving an incidence rate of 8.87\% [95\% confidence interval (Cl): 6.45-12.19] per 1,000 person-years. A stepwise relationship was found between incident diabetes and urbanicity as well as increasing economic status. The highest incidence of diabetes (13.57\%; 95\% Cl: 8.75-21.03 per 1,000 person-years) occurred among
\end{abstract}

subjects residing in urban areas, representing an adjusted relative risk of 4.25 (95\% Cl: 1.81-9.94) compared to those residing in rural areas. Also, compared with persons in the lowest economic group, those in the highest group had about a 3-fold elevated risk of having incident diabetes. Conclusion: Urban residence and increasing socioeconomic status are risk factors for new onset diabetes among elderly Nigerians. These social factors may be proxies for lifestyles that increase the likelihood of developing the disorder.

Copyright $\odot 2012$ S. Karger AG, Basel

\section{Background}

The global incidence and prevalence of diabetes continue to rise. At present, it is estimated that 366 million people have diabetes worldwide with a projection of 552 million by 2030 [1]. Prevalence is generally higher in men than women below 60 years of age but more women than men have diabetes due to the higher proportion of women aged more than 60 years with the disease [2]. Much of the projected rise in the incidence of diabetes is expected to occur in developing countries [2]. In Nigeria, prevalence of diabetes has more than doubled in about two decades [3]. According to the International Diabetes Federation, the highest prevalence of diabetes will be in the oldest age group between 60 and 79 years [4]. Diabetes is more likely to be underdiagnosed in the elderly population [5], a group more vulnerable to high rates of complications [6].

\section{KARGER \\ E-Mail karger@karger.ch} www.karger.com/ger

\section{(C) 2012 S. Karger AG, Basel \\ 0304-324X/13/0591-0003\$38.00/0}

Karger

Open access

This is an Open Access article licensed under the terms of the Creative Commons Attribution-NonCommercial 3.0 License (www.karger.com/OA-license-WT), applicable to the online version of the article only. Distribution for noncommercial purposes only.
Dr. W.O. Balogun

OR Department of Medicine, University College Hospital PO Box 14425

PMB 5116 Ibadan (Nigeria)

Tel. +234 803377 6720, E-Mail balogee@yahoo.com 


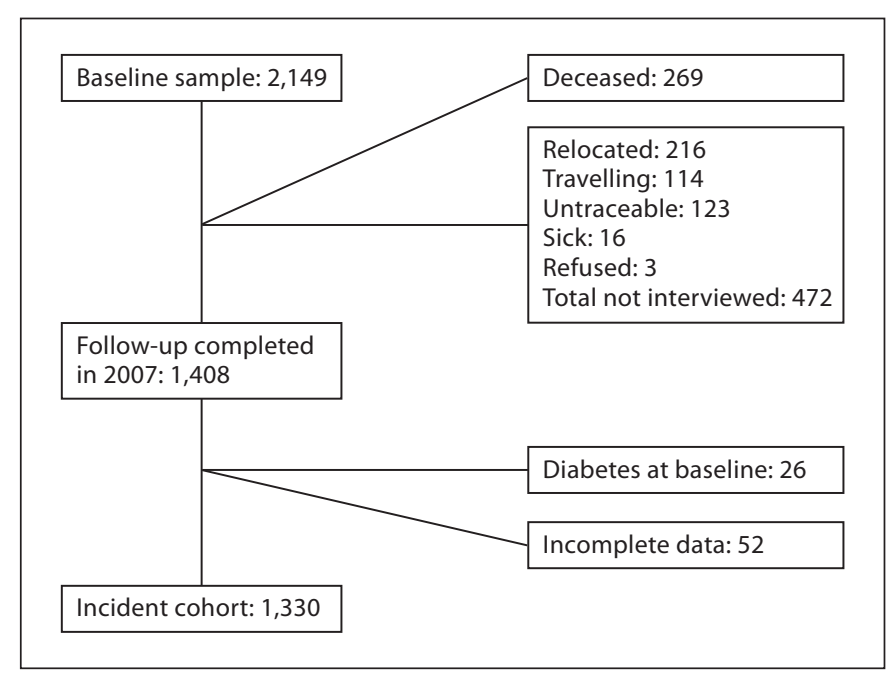

Fig. 1. Study flowchart.

Environmental exposures are the major factors driving the diabetes epidemic. The high prevalence of diabetes is due to population growth, aging, urbanization, increasing prevalence of obesity and physical inactivity [2]. For example, studies have shown the increased risk of diabetes among persons residing in urban areas and an inverse relationship between the disease and socioeconomic status (SES) [7-11]. It is unclear whether these associations are true of developing countries, such as Nigeria. Other than a rapidly growing elderly population, these countries are experiencing rapid urbanization as well as changes in social and lifestyle factors of potential relevance to the occurrence of diabetes. In this prospective cohort study, we explore the link between urban residence, SES and incident diabetes among older community dwellers.

\section{Research Design and Methods}

\section{Study Population}

The Ibadan Study of Ageing is a community study of the profile and determinants of healthy ageing. A full description of the baseline methodology conducted between August 2003 and November 2004 has been provided elsewhere $[12,13]$. In brief, a clustered multistage random sampling of households was employed to select a representative sample of noninstitutionalized older persons (aged 65 years and older). The resulting cohort of 2,149 with full data was followed up in 2007. Of the 2,149, 1,408 (65.5\%) were successfully followed up approximately 3 years later; 269 had died, while 453 could either not be traced, were travelling or had moved, 16 were too sick to be examined and 3 refused to be interviewed. Data from 52 subjects were later discovered to be incomplete; the majority of these were duplicated identification num- bers which were excluded from analysis. Also excluded were the 26 subjects who reported having diabetes at baseline. The result of the follow-up exercise is shown in figure 1 .

\section{Instruments}

Diabetes Status. Using a series of questions adapted from the US Health Interview Survey [14], we asked respondents about the presence of selected chronic conditions. In regard to diabetes, respondents were asked if a doctor or other health professional had ever told them they had diabetes. Previous studies have shown that self-report of diabetes showed very high agreement with medical records data (kappa $=0.82)[14]$ as well as yielding high agreement $(\mathrm{kappa}=0.86)$ when compared with physical examination and glycosylated hemoglobin [15]. Nevertheless, we note that compared to medical and laboratory records, self-reports often produce underestimates of diabetes prevalence [16]. This may be the case in our resource-constrained setting where access to medical service is limited.

All aspects of the study were approved by the University of Ibadan/University College Hospital, Ibadan Joint Ethical Review Board.

\section{Statistical Analysis}

Follow-up assessments were conducted on average 39.3 months [95\% confidence interval (CI): 39.1-39.5] after baseline interviews. Incidence rates were calculated by dividing the number of cases with the onset of diabetes in each group of interest by the number of person-years of observation in that group. The personyears at risk for an individual with diabetes were calculated as the midpoint between baseline and the follow-up time. Incidence rates were calculated within gender groups and four age categories (65-69, 70-74, 75-79, and 80 and older).

Baseline risk factors for incident diabetes were explored using logistic regression and the results are presented as relative risks (adjusted for age and sex) with 95\% CIs. All the CIs reported are adjusted for design effects. All analyses were conducted with the STATA statistical package (StataCorp, Stata Statistical Software, version 7.0 for windows; Stata, College Station, Tex., 2001). Economic status and residence were classified as in our previous reports $[12,13]$. Briefly, we took an inventory of 21 household and personal items, a standard and validated method of estimating the economic wealth of older persons in low income settings [17]. Respondents' economic status is categorized by relating each respondent's total possessions to the median number of possessions of the entire sample. Thus, economic status is rated low if its ratio to the median is 0.5 or less, low-average if the ratio is $0.5-1.0$, high-average if it is 1.0-2.0, and high if it is over 2.0. Residence was classified as rural (less than 12,000 households), semiurban (12,000-20,000 households) and urban (greater than 20,000 households).

\section{Results}

A total of 1,330 subjects comprising 615 (46.2\%) males and $715(53.8 \%)$ females were studied. The mean age (SE) was $77.3(0.3)$ years. A total of $450(33.8 \%)$ resided in the rural areas while 569 and 311 (42.8 and 23.4\%), respectively, resided in semiurban and urban areas. Relatively 
Table 1. SES and place of residence in relation to incidence rates of diabetes by 2007

\begin{tabular}{lccc}
\hline Characteristics & $\mathrm{N}$ & $\mathrm{n}$ & $\begin{array}{l}\text { Incidence rates per } \\
1,000 \text { years at risk } \\
\%(95 \% \mathrm{CI})\end{array}$ \\
& & & $8.87(6.45-12.19)$ \\
\hline $\begin{array}{l}\text { Total sample } \\
\text { Sex }\end{array}$ & 1,330 & 38 & $10.64(6.94-16.32)$ \\
$\quad$ Males & 615 & 21 & $7.35(4.57-11.82)$ \\
$\quad$ Females & 715 & 17 & $7.07(3.37-14.83)$ \\
Residence & & & $6.04(3.34-10.91)$ \\
$\quad$ Rural & 689 & 7 & $13.57(8.75-21.03)$ \\
$\quad$ Semiurban & 832 & 11 & $5.83(2.78-12.23)$ \\
$\quad$ Urban & 522 & 20 & $8.04(4.67-13.85)$ \\
SES & 367 & 7 & $9.83(5.29-18.27)$ \\
$\quad$ Low & 501 & 13 & $17.70(8.85-35.39)$ \\
$\quad$ Low average & 319 & 10 & 8 \\
$\quad$ High average & 143 & 8 & \\
$\quad$ High & & & \\
\hline$\quad$ N = Total number of subjects; $\mathrm{n}=$ number with specific char- \\
acteristic.
\end{tabular}

more people (868 or $65.3 \%$ ) were of the low socioeconomic strata, i.e. low and low average combined, while 462 or $34.7 \%$ belonged to the high (combined high average and high) socioeconomic strata. The demographic features of the total sample as well as the subsample with incident diabetes are shown in table 1 .

Table 1 also shows that 38 subjects developed diabetes after a follow-up period of about 3 years, giving a standardized incidence rate (SIR; total) of 8.87 (95\% CI: 6.4512.19) per 1,000 person-years. SIR was higher among males than females [10.64 (95\% CI: 6.94-16.32) vs. 7.35 (95\% CI: 4.57-11.82), respectively], but the difference was not statistically significant. The highest SIR of diabetes (13.57; 95\% CI: 8.75-21.03) occurred among subjects residing in the urban areas. SIR increased with increasing SES, with persons in the highest group having a rate of 17.70 (95\% CI: 8.85-35.38). There was no significant difference among subjects at different sites in terms of accessibility to healthcare services and reason for attrition.

Table 2 shows the results of the comparisons of the estimate of incident diabetes between groups based on residence and SES. There was a stepwise relationship between incident diabetes and residence with persons residing in urban centers having a 4 -fold increased risk compared to those in rural areas. Although not statistically significant, results in the socioeconomic strata showed that risk of diabetes increased as the subject moved up the SES ladder.
Table 2. Risk of developing diabetes according to place of residence and SES

\begin{tabular}{lll}
\hline & $\begin{array}{l}\text { Adjusted relative } \\
\text { risk }(95 \% \mathrm{CI})^{1}\end{array}$ & p value \\
\hline Residence & & \\
$\quad$ Rural & 1 & - \\
$\quad$ Semiurban & $1.27(0.49-3.31)$ & 0.62 \\
$\quad$ Urban & $4.25(1.81-9.94)$ & 0.001 \\
SES & & \\
$\quad$ Low & 1 & - \\
$\quad$ Low average & $1.29(0.53-3.17)$ & 0.58 \\
High average & $1.48(0.58-3.76)$ & 0.41 \\
High & $2.62(0.98-7.00)$ & 0.05 \\
\hline
\end{tabular}

${ }^{1}$ Adjusted for age, sex and educational group.

After adjustment for age, sex and educational group, subjects residing in the urban centers still had a 4.1 risk of developing diabetes $(\mathrm{p}=0.001)$ while the steady increment in the risk of incident diabetes persisted as SES improved $(\mathrm{HR}=2.61$ for highest SES, $\mathrm{p}=0.057)$.

\section{Discussion and Conclusions}

Findings in our study showed that the SIR of self-reported diabetes in this Nigerian cohort of elderly persons followed up for just over 3 years was 8.87 (95\% CI: 6.4912.19) per 1,000 person-years. Urban residence was a risk factor for incident diabetes. The incidence of diabetes increased nonsignificantly with increasing economic status.

There are only very few incidence studies of diabetes in Africans and none was found among Nigerians. Motala et al. [18] reported a cumulative incidence of $9.5 \%$ after a 10 year follow-up of 517 South African Indians aged 15 years and above. Another study in Tanzania reported an incidence of $11.5 \%$ over 50 months of follow-up in a cohort of 807 subjects aged 40 years and above [19] (or an annualized rate of about 2.9\%). Our incidence rate is just over the rate obtained in the South African sample but lower than was reported in the Tanzanian study. However, neither of these two studies focused specifically on the elderly. Although no data were found on the incidence of diabetes in Nigerians, there, however, appears to be a rise in prevalence [20, 21]. The only nationwide prevalence study in Nigeria so far was done [20] almost 2 decades ago and recorded 2.2\%.

To the best of our knowledge this is the first prospective incidence study to report the possible impact of ur- 
banization and SES on the occurrence of diabetes among ageing Nigerians. Demographic changes, increasing urbanization, and 'Western' dietary habits have variously been reported as contributing to the rising incidence of diabetes in Africans [18, 22, 23]. Physical inactivity, a well-known predisposing factor for developing diabetes as a result of obesity, is commonly associated with urban residence. A cross-sectional study [24] involving the elderly (55 years and above) in the same south-western region of Nigeria where our study was carried out reported higher physical inactivity in urban dwellers compared to their rural counterparts (62 and $83 \%$ for urban males and females vs. 22 and $50 \%$ for rural dwellers, respectively). In that same study, insulin resistance - a precursor to diabetes - was higher among urban dwellers, although Ezenwaka et al. [24] reported generally low levels of blood glucose and lipids among their subjects. They attributed this to reliance on healthier local food such as grains, vegetables and minimal red meat. Unlike this study by Ezenwaka et al., we conducted a prospective study involving relatively older subjects. Many ageing persons in Nigeria practice farming. It would not be surprising therefore if more of the subjects became physically inactive after migration to semiurban and urban areas where land and the opportunity for farming are in short supply. The researchers in Tanzania also identified physical inactivity and ageing among others as notable predisposing factors for the development of diabetes among their subjects [19]. Obesity, especially in women, was a strong predisposing factor for the future occurrence of diabetes among South African Indians [18]. Although both the studies among the Tanzanians and South Africans were longitudinal by design similar to our own, they were not exclusive for ageing subjects. A more recent cross-sectional study carried out among adult urban dwellers in the southern region of Nigeria reported that a family history of diabetes, physical inactivity, heavy consumption of alcohol, older age as well as high social status and Hausa-Fulani or Ibibio origin were associated with a significantly higher prevalence of type 2 diabetes [21]. Similar to our study, subjects in the highest socioeconomic class of the aforementioned study showed a significantly higher prevalence of type 2 diabetes when compared with the others [21].

Unlike others, we did not find an inverse relationship between SES and incident type 2 diabetes $[10,25,26]$. It would appear from the literature, as previously cited, that the inverse relationship between occurrence of diabetes and SES has been more commonly demonstrated among younger people (and not older people as in our study), and especially women, in developed countries. On the other hand, one prospective study carried out among 887 elderly German subjects aged 55-74 years and followed up for about 7 years found no association between incident type 2 diabetes and socioeconomic groups [27]. It would appear that there is more evidence in support of an inverse relationship between SES and prevalence rather than incidence of diabetes in the developed world $[28,29]$. It is plausible to suspect that this may have to do with differential survival following the onset of diabetes with persons in the higher economic groups more likely to survive, thus resulting in higher prevalence, rather than incidence, among them. It is nevertheless not difficult to see why the risk factors that we have identified will be germane to the development of new onset of diabetes. Persons residing in urban areas are more likely to live sedentary lifestyles and those in higher economic groups are more likely to abandon traditional cereal-based diets for processed high-calorie foods. On the other hand, it is also possible that people with higher SES and residing in urban areas are likely to be screened for diabetes because of better access to healthcare facilities.

Our study has strengths and weaknesses that are germane to the interpretation of our findings. One obvious limitation is that incident diabetes was ascertained by self-report. In a setting with highly limited access to medical care, it is likely that we have underreported the rate of incident diabetes in the group. On the other hand, there can be reasonable assurance about the validity of such self-reporting. Studies have reported high agreement in terms of sensitivity and specificity between selfreports of chronic conditions, especially diabetes, and medical criteria of diagnosis of these conditions $[15,16]$. Furthermore Goldman et al. [16] showed marginal underestimates of those who self-reported diabetes and those who were diagnosed based on fulfilling medical criteria ( 14.5 vs. $15.5 \%$, respectively). Another limitation is the extent to which our findings can be generalized to the larger Nigerian society. Given the widely differing rates of urbanization and cultural practices (including diets and lifestyles) in the country, with the south-west being among the most urbanized regions, it cannot be assumed that the rate we have reported is generalizable to the entire country. However, ours represents the largest such community-based study of older persons in the country, and indeed, to the best our knowledge, in subSaharan Africa and the results thus offer some insight into the occurrence of and risk factors for diabetes in this largely understudied population. Lastly, a small number of incident cases of diabetes were found and a limited number of risk factors were studied. It is also not impos- 
sible that some of the cases lost to follow-up may have had diabetes or some of the deaths may have been due to diabetes complications but we expect this not to have significantly affected the results. Also it may be argued that probably those in rural areas or having low SES were likely to lack awareness of diabetes due to limited access to healthcare. However, further analysis showed that there was no significant difference among subjects residing in various centers in terms of access to healthcare.

In conclusion, we have reported a fairly high incidence rate of type 2 diabetes among a rather neglected group, the older population. We have shown that urban life and increasing SES are likely risk factors for new onset of diabetes. As the population of the older persons increases in Nigeria, there is an urgent need to encourage increased physical activity and consumption of a balanced low-energy and cereal-based diet characteristic of the traditional African society so that the rising incidence and prevalence of diabetes can be stemmed.

\section{Disclosure Statement}

The Ibadan Study of Ageing is funded by a grant from the Wellcome Trust.

\section{References}

1 International Diabetes Federation (IDF): Di- 11 Krishnan S, Cozier YC, Rosenberg L, Palmer abetes Atlas 2010. www.idf.org (accessed May 16, 2012).

$>2$ Wild S, Roglic G, Green A, Sicree R, King H: Global prevalence of diabetes: estimates for the year 2000 and projections for 2030. Diabetes Care 2004;27:1047-1053.

$\checkmark 3$ Nyenwe EA, Odia OA, Ihekwaba AE, Ojule A, Babatunde S: Type 2 diabetes in adult Nigerians: a study of its prevalence and risk factors in Port Harcourt, Nigeria. Diabetes Res Clin Pract 2003;62:177-185.

4 IDF: Diabetes Atlas, ed 4. Brussels, International Diabetes Federation, 2009.

$\checkmark 5$ Cowie CC, Rust KF, Byrd-Holt DD, Eberhardt MS, Flegal KM, Engelgau MM, et al: Prevalence of diabetes and impaired fasting glucose in adults in the US population: $\mathrm{Na}$ tional Health and Nutrition Examination Survey 1999-2002. Diabetes Care 2006;29: 1263-1268.

6 Bethel MA, Sloan FA, Belsky D, Feinglos $\mathrm{MN}$ : Longitudinal incidence and prevalence of adverse outcomes of diabetes mellitus in elderly patients. Arch Intern Med 2007;167: 921-927.

7 Sobngwi E, Mbanya J, Unwin NC, Porcher R, Kengne A, Fezeu L, Minkoulou EM, et al: Exposure over the life course to an urban environment and its relation with obesity, diabetes, and hypertension in rural and urban Cameroon. Int J Epidemiol 2004;33:769-776.

8 United Nations Population Fund: State of world population 2007: unleashing the potential of urban growth. http://www.unfpa. org/swp/2007/english/introduction.html.

$>9$ Omran AR: The epidemiologic transition: a theory of the epidemiology of population change. Milbank Q 2005;83:731-757.

10 Connolly V, Unwin N, Sherriff P, Bilous R, Kelly W: Diabetes prevalence and socioeconomic status: a population based study showing increased prevalence of type 2 diabetes mellitus in deprived areas. J Epidemiol Commun Health 2000;54:173-177.
JR: Socioeconomic status and incidence of type 2 diabetes: results from the Black Women's Health Study. Am J Epidemiol 2010;171: 564-570.

12 Gureje O, Kola L, Afolabi E: Epidemiology of major depressive disorder in the Ibadan Study of Aging. Lancet 2007;370:957-964.

13 Gureje O, Ademola A, Olley BO: Depression and disability: comparisons with common physical conditions in the Ibadan Study of Aging. J Am Geriatr Soc 2008;56:2033-2038.

14 National Center for Health Statistics: Evaluation of National Health Interview Survey diagnostic reporting. Vital Health Stat 2 1994;120:1-116.

15 Wu SC, Li CY, Ke DS: The agreement between self-reporting and clinical diagnosis for selected medical conditions among elderly in Taiwan. Public Health 2000;114:137142 .

16 Goldman N, Lin IF, Weinstein M, Lin YH: Evaluating the quality of self-reports of hypertension and diabetes. J Clin Epidemiol 2003;56:148-154.

17 Ferguson BD, Tandon A, Gakidou E, Murray CJL: Estimating permanent income using indicator variables; in Murray CJL, Evans DB (eds): Health Systems Performance Assessment: Debates, Methods and Empiricism. Geneva, World Health Organization, 2003.

18 Motala AA, Pirie FJ, Gouws E, Amod A, Omar MA: High incidence of type 2 diabetes mellitus in South African Indians: a 10-year follow-up study. Diabet Med 2003;20:23-30.

19 Longo-Mbenza B, On'kin JB, Okwe AN, Kabangu NK, Fuele SM: Metabolic syndrome, aging, physical inactivity, and incidence of type 2 diabetes in general African population. Diab Vasc Dis Res 2010;7:28-39.

20 Akinkugbe OO (ed): National Expert Committee on Non-Communicable Diseases: Hypertension and Diabetes Mellitus. Lagos, Federal Ministry of Health, 1997, pp 64-90.
21 Nyenwe EA, Odia OJ, Ihekwaba AE, Ojule A, Babatunde S: Type 2 diabetes in adult Nigerians: a study of its prevalence and risk factors in Port Harcourt, Nigeria. Diabetes Res Clin Pract 2003;62:177-185.

22 Omran AR: The epidemiology transition, the key of the epidemiology population change. Milibank Memorial Fund Q 1971;49: 509-538.

23 Moore M, Gould P, Keary BS: Global urbanization and impact on health. Int J Hyg Environ Health 2003;206:269-278.

24 Ezenwaka CE, Akanji AO, Akanji BO, Unwin NC, Adejuwon CA: The prevalence of insulin resistance and other cardiovascular disease risk factors in healthy elderly southwestern Nigerians. Atherosclerosis 1997; 128:201-211.

25 Lidfeldt J, Li TY, Hu FB, Manson JE, Kawachi I: A prospective study of childhood and adult socioeconomic status and incidence of type 2 diabetes in women. Am J Epidemiol 2007; 165:882-889.

26 Maty SC, Lynch JW, Raghunathan TE, Kaplan GA: Childhood socioeconomic position, gender, adult body mass index, and incidence of type 2 diabetes mellitus over 34 years in the Alameda County Study. Am J Public Health 2008;98:1486-1494.

27 Kowall B, Rathmann W, Strassburger K, Meisinger C, Holle R, Mieck A: Socioeconomic status is not associated with type 2 diabetes incidence in an elderly population in Germany: KORA S4/F4 Cohort Study. J Epidemiol Community Health 2011;65:606612

28 Cowie CC, Eberhardt MS: Sociodemographic characteristics of persons with diabetes; in National Diabetes Data Group. Diabetes in America, ed 2. Bethesda, National Institutes of Health, 1995, pp 85-116.

29 Davidson MB: The disproportionate burden of diabetes in African-American and Hispanic populations. Ethn Dis 2001;11:148151. 